\title{
Pretreatment lymphocyte-to-monocyte ratio as a predictor of survival among patients with ovarian cancer: a meta-analysis
}

This article was published in the following Dove Medical Press journal: Cancer Management and Research

\author{
Xu-ping Gaol,* \\ Yan-hua Liu',* \\ Ze-ying Liu' \\ Li-jun Wang ${ }^{3}$ \\ Chun-xia Jing' \\ Sui Zhu ${ }^{4}$ \\ Fang-fang Zeng' \\ 'Department of Epidemiology, \\ School of Medicine, Jinan University, \\ Guangzhou 510632, Guangdong, \\ China; ${ }^{2}$ Department of Nutrition, \\ The First Affiliated Hospital of \\ Zhengzhou University, Zhengzhou \\ 450052, Henan, China; ${ }^{3}$ Department \\ of Nutrition, School of Medicine, \\ Jinan University, Guangzhou 510632, \\ Guangdong, China; ${ }^{4}$ Department of \\ Medical Statistics, School of Medicine, \\ Jinan University, Guangzhou 510632, \\ Guangdong, China
}

*These authors contributed equally to this work

Correspondence: Fang-fang Zeng Department of Epidemiology, School of Medicine, Jinan University, No. 60I Huangpu Road West, Guangzhou 510632, Guangdong, China

Tel +862085226335

Fax +86 208522 I343

Email zengffju@|26.com

Sui Zhu

Department of Medical Statistics, School of Medicine, Jinan University, No. 60I

Huangpu Road West, Guangzhou 510632 .

Guangdong, China

Tel +86208522 6335

Fax +86 $208522 \quad$ I343

Email zhusuil2I3@|26.com
Introduction: In this meta-analysis, we analyzed retrospective cohort studies that assessed the prognostic potential of the pretreatment lymphocyte-to-monocyte ratio (LMR) among patients with ovarian cancer (OC).

Materials and methods: We comprehensively searched electronic databases, including PubMed and Embase, from inception through October 2018. A random-effects model was used to calculate pooled HRs and their $95 \%$ CIs for overall survival (OS) and progression-free survival (PFS). The low LMR group was treated as the reference group.

Results: Twelve studies, including 3,346 OC cases at baseline, were included. Overall, our results indicated that LMR was positively associated with both OS (HR: 1.85, 95\% CI: 1.50-2.28, $P<0.001 ; I^{2}=76.5 \%$ ) and PFS (HR: $1.70,95 \%$ CI: $1.49-1.94, P<0.001 ; P=24.4 \%$ ) among OC patients. Stratified analyses indicated that, for OS, the LMR's protective effect was more evident in studies conducted among younger patients ( $<55$ years) than in those conducted among older patients $(\geq 55$ years; $P$ for interaction $=0.017$ ), which was confirmed by meta-regression analysis $(P=0.004)$.

Conclusion: This study suggested that a higher pretreatment LMR level was associated with a favorable prognosis among OC patients. Future large-scale prospective clinical trials are needed to confirm the prognostic value of LMR among OC patients.

Keywords: ovarian cancer, lymphocyte-to-monocyte ratio, prognosis, meta-analysis

\section{Introduction}

Ovarian cancer (OC) is the fifth most common cause of cancer-related deaths among women, with $\sim 90 \%$ of these cases being epithelial ovarian cancer (EOC). ${ }^{1}$ At the start of 2018, there were an estimated 22,240 newly diagnosed cases and 14,070 deaths due to $\mathrm{OC}$ in USA. ${ }^{1}$ Although $\mathrm{OC}$ is less common than other cancers such as breast cancer, $\mathrm{OC}$ is attracting increased attention because of its poor prognosis. The 5 -year survival rate for $\mathrm{OC}$ is only $47.2 \%$. Although great progress has been made in cancer research, the overall prognosis for $\mathrm{OC}$ remains poor, because it is often diagnosed late in the disease process and has high recurrence rates after curative resection. ${ }^{2}$ Therefore, more effective and convenient markers must be identified to estimate the prognosis and select appropriate treatment strategies.

Over the past decades, many theories have been postulated to explain OC's etiology, and most of them converge on the role of inflammation. ${ }^{3}$ The systemic inflammatory response is associated with survival in advanced and localized cancers. ${ }^{4}$ Cancer-related inflammation includes modulating inflammatory cells and mediators such as cytokines 
and chemokines; however, these markers are not routinely measured despite their direct changes provide a direct surrogate marker of expression (eg, lymphocyte-to-monocyte ratio $[\mathrm{LMR}]) .{ }^{4}$ Several recent studies assessed the prognostic effect of pretreatment LMR among patients with OC, but the results were inconsistent. Elevated LMR was shown to increase survival in some, ${ }^{5-7}$ but not all, ${ }^{8-11}$ studies. As the statistical power of an individual study may be too weak to identify associations between pretreatment LMR and OC patient survival (sample size of most included studies was $<300$ OC patients), a meta-analysis combining data from all published studies may be more convincing.

Thus, we conducted a meta-analysis to evaluate the prognostic effect of pretreatment LMR on OC patient survival, which included all eligible publications to date.

\section{Materials and methods}

This meta-analysis was conducted in accordance with the PRISMA (Table S1). ${ }^{12}$

\section{Search strategies}

A comprehensive literature search of PubMed, Embase, Web of Science, Chinese National Knowledge Infrastructure (CNKI, http://www.cnki.net), and the Wanfang databases (http://www.wanfangdata.com.cn) was conducted from inception through October 2018. The following search terms were used: (lymphocyte-to-monocyte or lymphocyte monocyte or lymphocyte-monocyte or lymphocyte to monocyte or lymphocyte/monocyte or LMR) AND (cancer* or carcinoma* or neoplasm* or malignan* or tumour* or tumor*) AND (ovary or ovarian) without language restriction (Supplementary materials). Related articles generated by Google Scholar (http://scholar.google.com) and PubMed were retrieved. We also scanned the reference lists of related articles to identify all potential useful studies on OC that might have been missed in our database searches.

\section{Study selection}

Inclusion criteria were as follows: 1) studies on patients with OC diagnosed histopathologically; 2) studies that assessed the prognostic value of pretreatment LMR among OC patients; 3) studies that reported the LMR cutoff value; 4) studies that reported sufficient information for calculating the $\mathrm{HR}$ and its $95 \% \mathrm{CI}$; and 5) studies that used overall survival (OS) and/or progression-free survival (PFS) as outcomes. For studies with overlapping data, only the most relevant articles with the largest datasets were included in the final analysis.

\section{Data extraction}

Two independent reviewers (X-PG and Y-HL) evaluated all potential articles for inclusion. Disagreements were resolved by discussion among all coauthors. The following information was collected: the first author's name, publication year, country (region) and ethnicity of the population, publication type, number of OC patients at baseline, age, year of recruitment, time of follow-up, treatment method, tumor stage, histological type, LMR cutoff value, method of obtaining cutoff value, OC diagnostic criteria, survival analysis methods, and prognostic end points (OS or PFS). HRs were extracted from multivariate or univariate analyses or Kaplan-Meier survival curves. If only Kaplan-Meier curves were provided, we extracted data from the survival curves using Engauge Digitizer v.4.1 software. ${ }^{13}$

\section{Quality assessment}

Each study's methodological quality was assessed as per the Newcastle-Ottawa Scale (NOS), ${ }^{14}$ which was used to allocate a maximum of nine stars for selection quality of the study population, comparability, and outcome. The studies' quality scores ranged from 0 to 9 , with 7-9 points indicating a highquality study and $0-6$ points indicating a low-quality study.

\section{Statistical analyses}

The DerSimonian and Laird random-effects model of inverse variance methods was used to estimate the pooled HRs and 95\% CIs. Unless otherwise stated, we used the most fully adjusted RRs from each study, and the low LMR group was treated as the reference group. If the studies used different reference groups to estimate the LMR HR for OS/PFS, we used an Excel macro file to transform the reference group. ${ }^{15}$

The random-effects model was chosen a priori, because it is considered to be more conservative than the fixed-effects model and it accounts for both within- and between-study heterogeneity. ${ }^{16}$ Between-study heterogeneity was tested using Cochran's $Q$ test and Higgins $I^{2}$ statistic (higher $I^{2}$ values denote greater heterogeneity). ${ }^{17}$ We performed subgroup analyses for both OS and PFS to examine the robustness of the results by age ( $<55$ vs $\geq 55$ years), LMR cutoff value ( $\leq 3.0$ vs $>3.0$ ), sample size ( $\leq 200$ vs $>200$ ), and NOS score ( $<7$ and $\geq 7$ points). Influence analysis was also conducted to assess the effect of a single study on the pooled estimates. ${ }^{18}$ These variables were also analyzed as covariates in the meta-regression analysis. Publication bias was assessed by visually inspecting funnel plots and quantitatively evaluated using Egger's and Begg's linear regression asymmetry tests. ${ }^{17}$ All data were analyzed using Stata software, version 11.0 
(StataCorp LP, College Station, TX, USA), and a two-sided $P<0.05$ was considered statistically significant.

\section{Results}

\section{Search results}

The electronic database searches identified 1,018 articles (Figure 1), of which 180 duplications were excluded by Endnote. After assessing titles and abstracts and screening full texts, 824 unrelated articles were excluded. For the remaining 14 potentially eligible articles, 2 duplicate studies, 1 duplicate study, ${ }^{19}$ and 1 study with incomplete data $^{20}$ were further excluded. Finally, 12 studies were included. ${ }^{5-11,21-25}$

\section{Characteristics of the included studies}

Table 1 summarizes the characteristics of the included studies. In total, 3,346 OC patients (weighted age: 55.8 years) were included, with a follow-up period ranging from 23.6 to 58 months. All studies were published in 2016 or later. The number of patients per study ranged from 42 to 672 . Eight studies were conducted among Chinese patients, three among Korean patients, and one among American Caucasian patients. The LMR cutoff values ranged from 1.85 to 4.35 . The overall NOS scores ranged from 5 to 8 points (Table S2). Most cases were EOC, and $76.5 \%$ were stage III/IV. Among these studies, three investigated only OS, while nine investigated both OS and PFS.

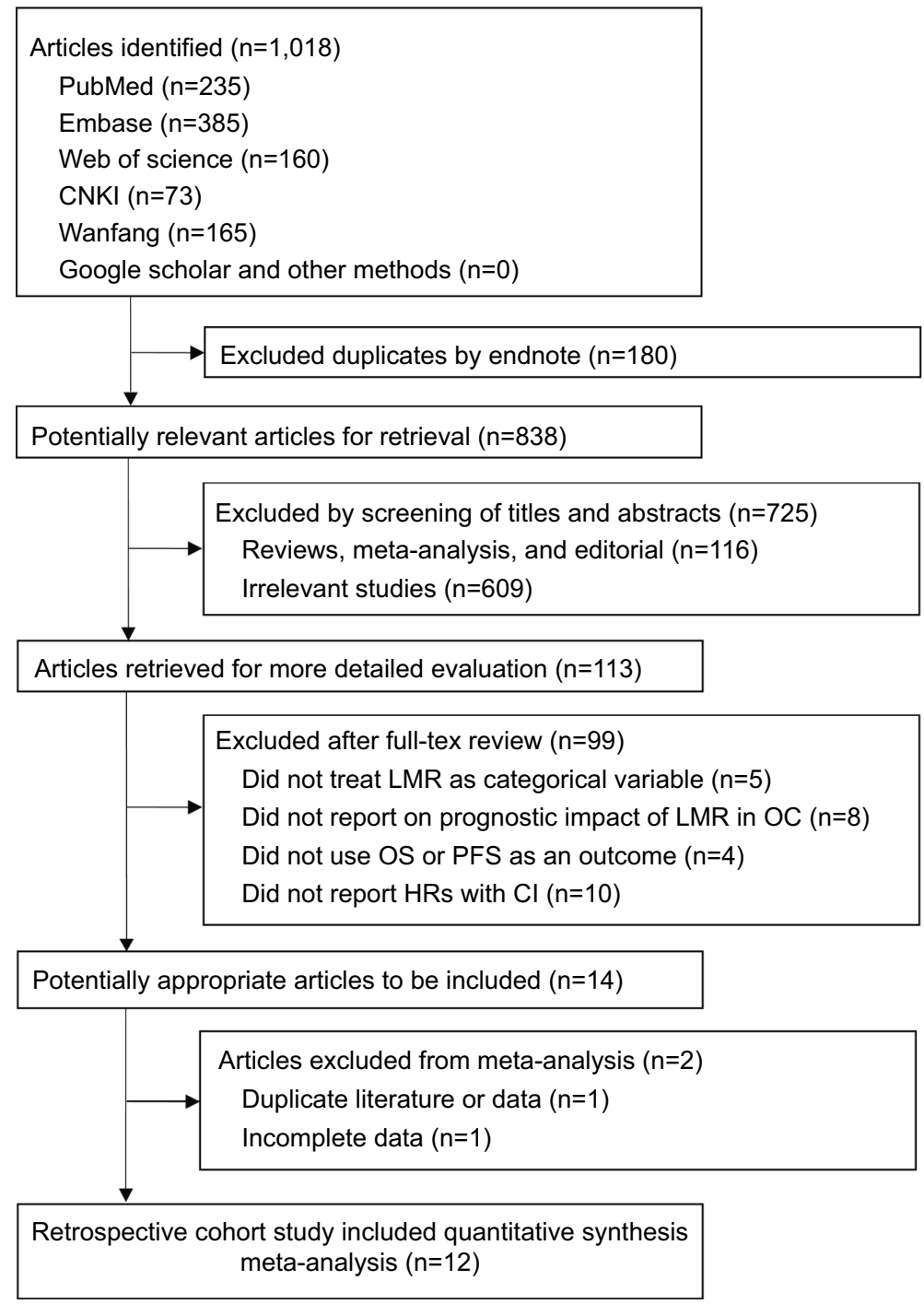

Figure I Flowchart of study selection in the current meta-analysis.

Abbreviations: CNKI, Chinese National Knowledge Infrastructure; LMR, lymphocyte-to-monocyte ratio; OC, ovarian cancer; OS, overall survival; PFS, progression-free survival. 


\begin{tabular}{|c|c|c|c|c|c|c|c|c|c|c|}
\hline $\begin{array}{ll}n \\
0 \\
0 \\
z\end{array}$ & 0 & 0 & $\circ$ & 0 & $\infty$ & 。 & n & $\Lambda$ & n & n \\
\hline 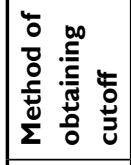 & 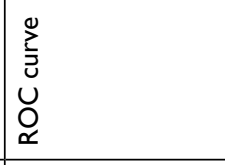 & 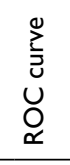 & 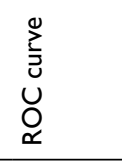 & 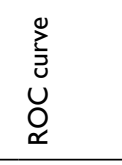 & 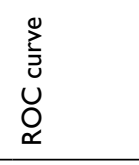 & 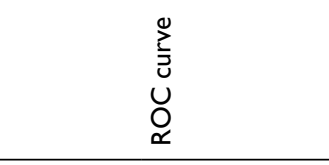 & 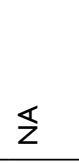 & 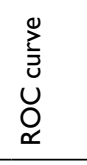 & 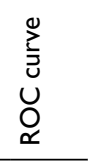 & 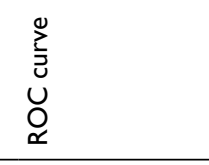 \\
\hline 总 & ì & $\stackrel{\leftrightarrow}{-}$ & $\begin{array}{l}\text { ờ } \\
\dot{m} \\
\dot{m}\end{array}$ & 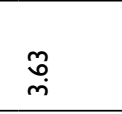 & $\tilde{\text { ส }}$ & $\stackrel{\stackrel{\leftrightarrow}{\tilde{\sigma}}}{\sigma}$ & $\underset{\sim}{\tilde{m}}$ & $\underset{m}{\stackrel{q}{2}}$ & $\stackrel{\stackrel{\infty}{\infty}}{m_{j}}$ & ồ \\
\hline 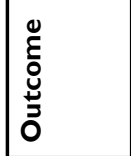 & 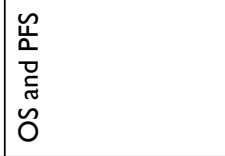 & 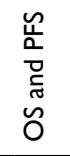 & ő & 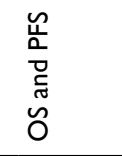 & 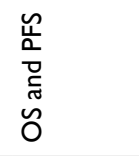 & oั & 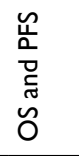 & 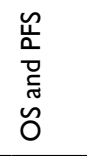 & ๕ั & 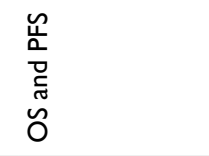 \\
\hline 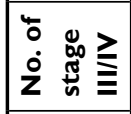 & $\underline{\underline{\underline{m}}}$ & $\Xi$ & $\underline{\overline{\mathbf{\omega}}}$ & f & $\stackrel{\tilde{M}}{n}$ & 8 & 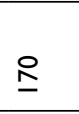 & สู & $\stackrel{\underline{n}}{=}$ & $\underline{\overline{\mathbf{\omega}}}$ \\
\hline $\begin{array}{ll} \\
\vdots \\
\dot{\delta} \\
z\end{array}$ & $a$ & 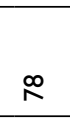 & in & 0 & $\overline{\underline{I}}$ & f & $\hat{6}$ & $\circ$ & $\alpha$ & $\stackrel{\infty}{.}$ \\
\hline 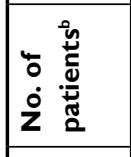 & 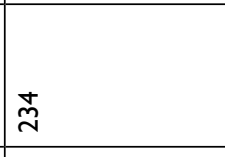 & $\stackrel{\propto}{\infty}$ & $\stackrel{8}{d}$ & F & 范 & $\stackrel{\Xi}{\Xi}$ & $\widehat{\tilde{N}}$ & $\tilde{6}$ & $\stackrel{+}{N}$ & $\stackrel{\text { i }}{0}$ \\
\hline 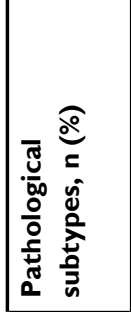 & 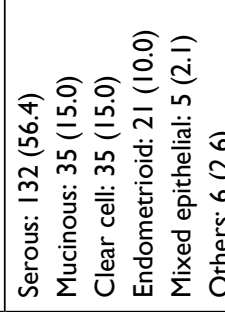 & 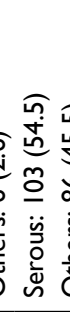 & 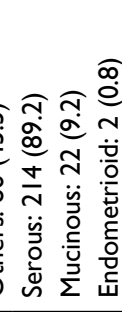 & 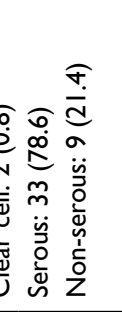 & 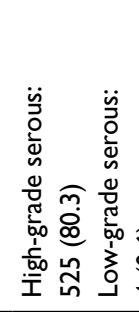 & 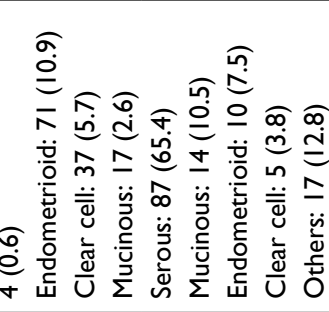 & 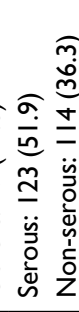 & 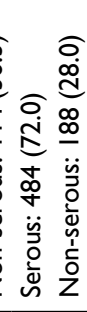 & 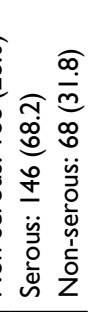 & 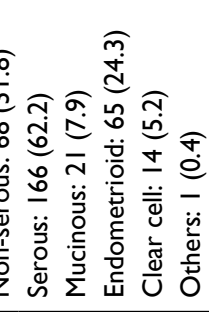 \\
\hline 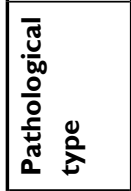 & \begin{tabular}{|}
$u$ \\
O.
\end{tabular} & 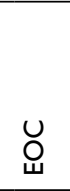 & ૫ & U. & U. & ○ & ○ & 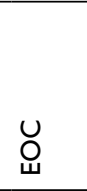 & U. & 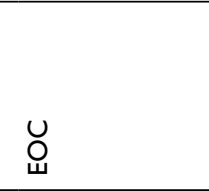 \\
\hline 乐 & 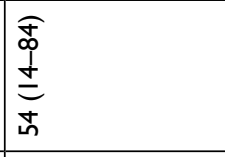 & 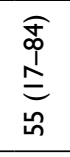 & $\begin{array}{l}\frac{\tilde{O}}{+1} \\
\frac{ \pm 1}{\dot{H}} \\
\end{array}$ & 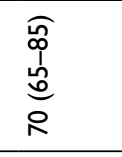 & 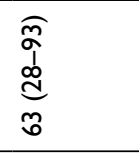 & 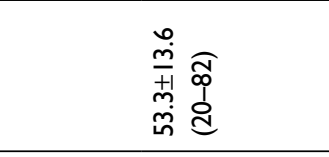 & 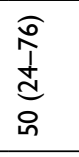 & 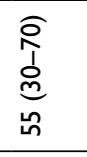 & 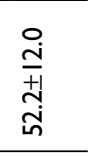 & 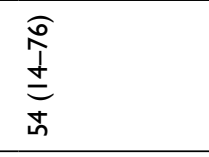 \\
\hline 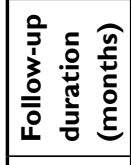 & $\underline{z}$ & $\underline{s}$ & $\mathbb{z}$ & 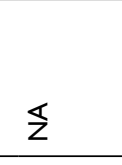 & 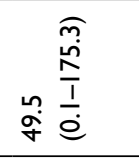 & 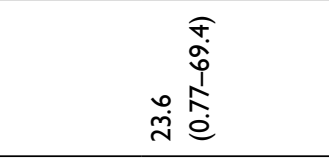 & $\mathbb{Z}$ & 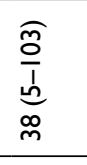 & 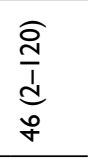 & 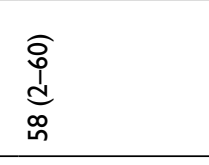 \\
\hline 势 & 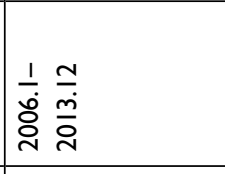 & 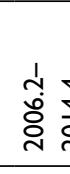 & $\frac{1}{0} \frac{2}{\frac{m}{2}}$ & 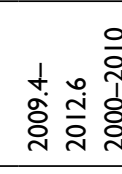 & $\begin{array}{l}0 \\
0 \\
1 \\
0 \\
0\end{array}$ & 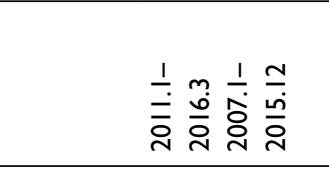 & & مُ & 青 & 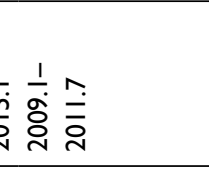 \\
\hline 童 & 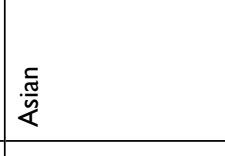 & $\frac{\frac{5}{2}}{\frac{\pi}{2}}$ & 总 & $\frac{5}{\frac{5}{2}}$ & 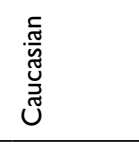 & $\frac{\frac{5}{9}}{\frac{9}{x}}$ & $\frac{\frac{\pi}{2}}{\frac{\pi}{4}}$ & $\frac{\frac{5}{6}}{\frac{3}{x}}$ & $\frac{5}{\frac{5}{2}}$ & 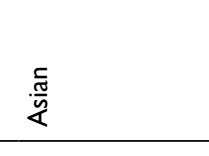 \\
\hline 童 & 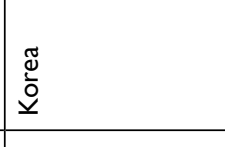 & 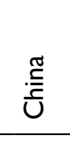 & 胥 & 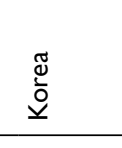 & 芯 & 趇 & 胥 & 愛 & 趇 & 䋃 \\
\hline ঠે & $\frac{1}{2}$ & $\stackrel{\circ}{\circ}$ & $\stackrel{\circ}{\stackrel{i}{0}}$ & $\overline{\bar{i}}$ & $\overline{\bar{i}}$ & $\overline{\bar{i}}$ & ì & $\bar{i}$ & $\overline{\grave{i}}$ & iे \\
\hline 咅 & 일 & $\begin{array}{l}0 \\
\vdots \\
5 \\
5 \\
5 \\
\end{array}$ & 然 & 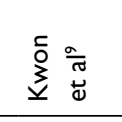 & כ & 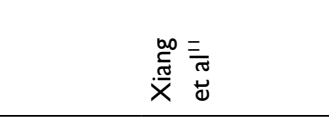 & & 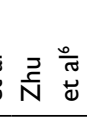 & & 施 \\
\hline
\end{tabular}




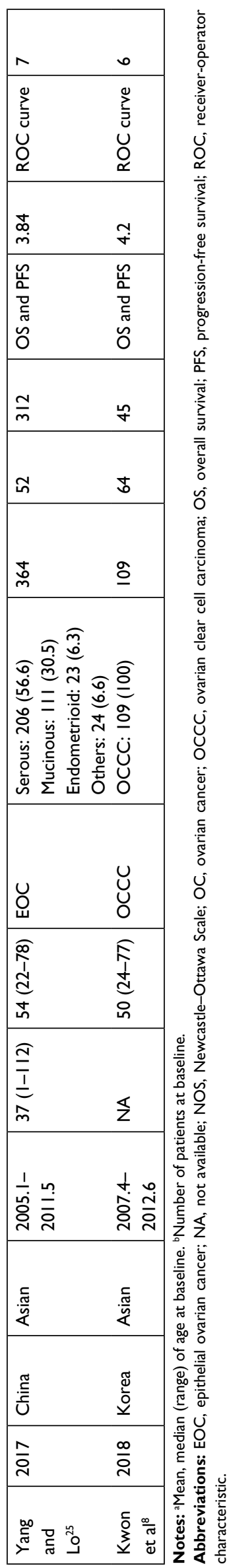

\section{Association between LMR and OS among OC patients}

Twelve studies involving 3,346 patients reported LMR and OS data among OC cases. ${ }^{5-11,21-25}$ Increased LMR was associated with improved OS (pooled HR: 1.85, 95\% CI: $1.50-2.28, P<0.001)$ with significant between-study heterogeneity $\left(P<0.001, I^{2}=76.5 \%\right.$; Table 2 and Figure 2A). The association persisted after reanalyzing studies among Asian patients or those with only EOC. Stratified analyses for age, LMR cutoff values, sample size, and NOS score revealed significant interactions for age ( $P$ for interaction $=0.017$ ) and LMR cutoff values $(P$ for interaction $=0.025$ ). The protective effect of elevated LMR was more evident among younger patients than older patients (HR: 2.28 vs 1.47) and among studies using an LMR cutoff of $>3.0$ than in those using $\leq 3.0$ (HR: $2.09 \mathrm{vs}$ 1.38). Meta-regression analysis further confirmed that age, but not LMR cutoff values, significantly contributed to inter-study heterogeneity $(P$ for regression $=0.004$ and 0.153; Table S3).

\section{Association between LMR and PFS in OC patients}

Eight studies $^{5-9,21,23,25}$ involving 2,114 patients reported data for the association between LMR and PFS among OC patients, and all studies were conducted among Asian patients. Similar to OS, the random-effects combined analysis demonstrated that LMR was positively and significantly associated with PFS (pooled HR: 1.70, 95\% CI: 1.49-1.94, $P<0.001)$ but with low between-study heterogeneity $\left(I^{2}=24.4 \% ; P=0.234\right.$; Table 2 and Figure 2B). The result was similar among studies with only EOC cases. Stratified analyses suggested that the association did not differ among NOS scores, LMR cutoff values, and age strata $(P$ interaction range $=0.066-0.987$ ). Meta-regression analysis also revealed that publication year, age, NOS score, sample size, and LMR cutoff value did not significantly contribute to heterogeneity ( $P$ for regression range $=0.086-0.982$ ).

\section{Sensitivity analysis and bias}

The sensitivity analyses indicated that the pooled HRs were not obviously influenced by any single study for either OS or PFS (Table 2).

Both Egger's and Begg's tests revealed no significant publication bias, and the $P$-values were 0.732 and 0.272 for OS and 1.000 and 0.887 for PFS. The funnel plots also showed no evidence of publication bias for either OS or PFS (Figure 3). 
Table 2 Total, stratified, and sensitivity analyses of the associations between pretreatment LMR and survival among OC patients

\begin{tabular}{|c|c|c|c|c|c|c|c|c|c|c|}
\hline \multirow[t]{2}{*}{ Groups } & \multicolumn{5}{|l|}{ OS } & \multicolumn{5}{|l|}{ PFS } \\
\hline & $\mathbf{N o}^{\mathbf{a}}$ & RR (95\% Cls) ${ }^{b}$ & $P^{c}$ & $I^{2}(\%)$ & $P^{d}$ & $\mathbf{N o}^{\mathbf{a}}$ & RR (95\% Cls) ${ }^{b}$ & $P^{c}$ & $I^{2}(\%)$ & $P^{d}$ \\
\hline Overall & $\mid 2^{5-11,2 \mid-25}$ & $1.85(1.50-2.28)$ & $<0.001$ & 76.5 & $<0.001$ & $8^{5-9,21,23,25}$ & $1.70(1.49-1.94)$ & $<0.001$ & 24.4 & 0.234 \\
\hline Asian only & $\left.1\right|^{5-9,11,21-25}$ & $1.97(1.62-2.40)$ & $<0.001$ & 67.0 & 0.001 & $8^{5-9,21,23,25}$ & $1.70(1.49-1.94)$ & $<0.001$ & 24.4 & 0.234 \\
\hline EOC only & $8^{6,7,9,10,21-23,25}$ & $1.69(1.34-2.13)$ & $<0.001$ & 79.4 & $<0.001$ & $6^{6,7,9,21,23,25}$ & $1.64(1.48-1.82)$ & $<0.001$ & 0.0 & 0.483 \\
\hline \multicolumn{11}{|l|}{ Subgroup analyses } \\
\hline \multicolumn{11}{|l|}{ Age (years) } \\
\hline$<55$ & $7^{5,7,8,11}, 22,23,25$ & $2.28(1.72-3.01)$ & $<0.001$ & 61.9 & 0.015 & $5^{5,7,8,23,25}$ & $1.74(1.37-2.20)$ & $<0.001$ & 54.7 & 0.065 \\
\hline$\geq 55$ & $5^{6,9,10,21,24}$ & $1.47(1.17-1.85)$ & 0.001 & 72.2 & 0.006 & $3^{6,9,21}$ & $1.70(1.50-1.94)$ & $<0.001$ & 0.0 & 0.811 \\
\hline \multicolumn{11}{|l|}{ LMR cutoff values } \\
\hline$\leq 3.0$ & $3^{7,10,21}$ & $1.38(1.06-1.80)$ & 0.015 & 64.0 & 0.062 & $2^{7,21}$ & 1.81 (1.1I-2.97) & 0.018 & 65.3 & 0.090 \\
\hline$>3.0$ & $9^{5,6,8,9,9,11,22-25}$ & $2.09(1.63-2.67)$ & $<0.001$ & 70.1 & 0.001 & $6^{5,6,8,9,23,25}$ & $1.72(1.48-1.99)$ & $<0.001$ & 18.0 & 0.297 \\
\hline \multicolumn{11}{|l|}{ Sample size } \\
\hline$\leq 200$ & $4^{8,9,11,21}$ & $1.59(0.99-2.56)$ & 0.057 & 37.8 & 0.186 & $3^{8,9,21}$ & $1.36(0.83-2.20)$ & 0.219 & 0.0 & 0.970 \\
\hline$>200$ & $8^{5-7,10,22-25}$ & $1.94(1.50-2.50)$ & $<0.001$ & 83.1 & $<0.001$ & $5^{5-7,23,25}$ & $1.74(1.48-2.06)$ & $<0.001$ & 52.0 & 0.080 \\
\hline \multicolumn{11}{|l|}{ NOS score } \\
\hline$<7$ & $7^{5,7-9,11,21,24}$ & $1.94(1.45-2.60)$ & $<0.001$ & 57.1 & 0.030 & $5^{5,7-9,21}$ & $2.06(1.65-2.59)$ & $<0.001$ & 0.0 & 0.429 \\
\hline$\geq 7$ & $5^{6,10,22,23,25}$ & $1.79(1.31-2.46)$ & $<0.001$ & 86.7 & $<0.001$ & $3^{6,23,25}$ & $1.63(1.46-1.81)$ & $<0.001$ & 0.0 & 0.379 \\
\hline \multicolumn{11}{|l|}{ Influence analyses } \\
\hline Minimal & - & $1.75(1.43-2.13)$ & $<0.001$ & 72.9 & $<0.001$ & - & I.64 (I.48-I.8I) & $<0.001$ & 0.0 & 0.560 \\
\hline Maximal & - & $1.97(1.62-2.40)$ & $<0.001$ & 67.0 & 0.001 & - & $1.76(1.51-2.05)$ & $<0.001$ & 23.0 & 0.254 \\
\hline
\end{tabular}

Notes: ${ }^{a}$ Number of studies. ${ }^{b} R R s$ and $95 \%$ Cls were pooled by using the random-effects model (the DerSimonian and Laird method). ${ }^{c} P$-value of $Z$-test for the significance of pooled RRs and $95 \% \mathrm{Cls}$. ${ }^{d} P$-value of $Q$-test for between-study heterogeneity test. elnfluence analysis was conducted by eliminating one study at a time; for OS, the excluded study was the study by Tang et $\mathrm{a}^{12}$ for minimal pooled RRs, and Li et al ${ }^{10}$ for the maximal pooled RRs; for PFS, the excluded study was the study by Zhang et al ${ }^{5}$ for minimal pooled RRs, and $\operatorname{Tian}^{23}$ for the maximal pooled RR.

Abbreviations: EOC, epithelial ovarian cancer; LMR, lymphocyte-to-monocyte ratio; NOS, Newcastle-Ottawa Scale; OC, ovarian cancer; OS, overall survival; PFS, progression-free survival.

\section{Discussion}

In this meta-analysis, we first report the prognostic value of pretreatment LMR among OC patients. Our results indicate that higher pretreatment LMR levels are associated with increased OS and PFS among OC patients. Substantial heterogeneity was observed for OS; further subgroup and meta-regression analyses indicated that age contributed to this heterogeneity, and these associations were more evident among younger patients than older populations.

In recent years, several prognostic indicators derived from peripheral blood, such as LMR, have been widely investigated as useful prognostic markers in cancers. LMR has been identified as an independent prognostic factor in patients with various cancers, such as head and neck, ${ }^{26}$ pancreatic, ${ }^{27}$ colorectal, ${ }^{28}$ hepatocellular, ${ }^{29}$ and breast cancers. ${ }^{30}$ Our results were consistent with findings from these studies, showing that higher LMR ratios may improve cancer prognoses.

The exact mechanisms by which LMR has some prognostic relevance in OC patients were still unknown. According to the current evidence, lymphopenia might weaken the efficacy of the immune system and be associated with worse prognosis in cancers; cell-mediated cytotoxicity may be attenuated if the level of effector T cells is insufficient. ${ }^{31}$ Circulating monocytes may contribute to both tumor growth and reduced immunosurveillance through differentiating into macrophages after infiltrating a tumor and then respond to the wide spectrum of chemokines and growth or differentiation factors. ${ }^{31}$ Thus, the prognostic effect of LMR among OC patients can be assumed to be related to tumor-infiltrating immune cells, such as tumor-infiltrating lymphocytes (TILs), or tumor-associated macrophages. Circulating TILs, as direct measures of intratumoral immunity, may contribute to cancer growth and spread. ${ }^{32}$ In OC tumor tissue sections, intraepithelial CD8+ TILs correlated with good outcome, and a high ratio of $\mathrm{CD} 8+/ \mathrm{FoxP} 3+\mathrm{T}$ regulatory cells was beneficial to survival. ${ }^{33}$ Recent epidemiological studies have also confirmed that the presence of TILs was associated with improved clinical outcomes in OC patients. ${ }^{34-36}$ Peripheral blood-based parameters (eg, LMR) have been studied as a surrogate measures of intratumoral immunity that reflect a host's immune response. ${ }^{4}$ LMR has been shown a statistically significant correlation with CD8+ TILs among patients with breast cancer. ${ }^{37}$ Tumor-associated macrophages (TAMs) have been suggested to be involved in accelerating angiogenesis, 
A OS

First author (year)

HR $(95 \% \mathrm{Cl}) \quad$ Weight (\%)

Eo WK (2016)

Sun L (2016)

Wang XJ (2016)

Kwon BS (2017)

Li Z (2017)

Xiang J (2017)

Zhang W (2017)

Zhu JY (2017)

Tang $Y(2017)$

Tian YJ (2017)

Yang HM (2017)

Kwon BS (2018)

Overall $\left(R^{2}=76.5 \%, P=0.000\right)$

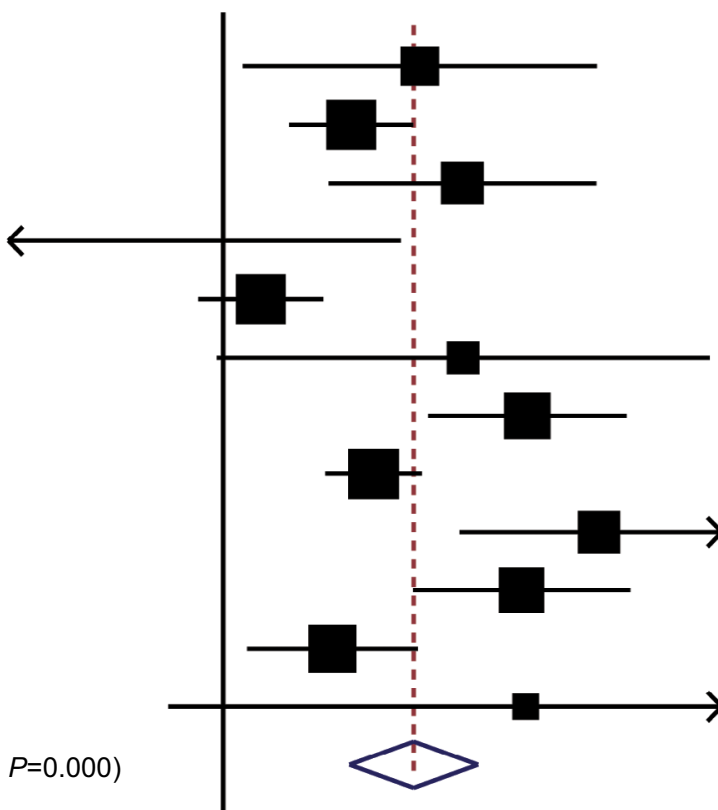

$1.89(1.07,3.34) \quad 6.70$

$1.51(1.24,1.85) \quad 12.10$

$2.16(1.41,3.34) \quad 8.56$

$0.33(0.06,1.77) \quad 1.38$

$1.13(0.92,1.38) \quad 12.08$

$2.17(0.98,4.81) \quad 4.53$

$2.67(1.94,3.68) \quad 10.28$

$1.63(1.39,1.90) \quad 12.66$

$3.36(2.14,5.28) \quad 8.30$

$2.62(1.85,3.72) \quad 9.81$

$1.42(1.08,1.87) \quad 10.99$

$2.65(0.84,8.41) \quad 2.61$

$1.85(1.50,2.28) \quad 100.00$

NOTE: Weights are from-random effects analysis

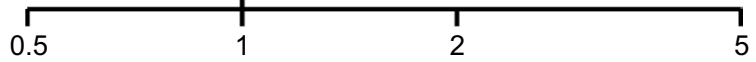

B PFS

First author (year)

HR $(95 \% \mathrm{Cl}) \quad$ Weight (\%)

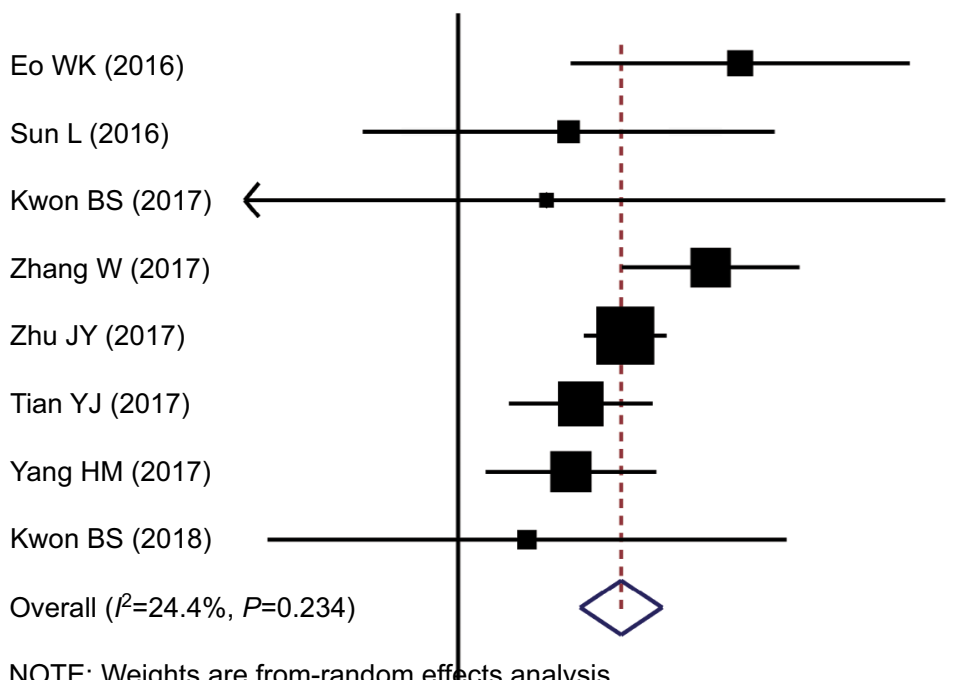

$2.50(1.44,4.34) \quad 5.28$

$1.43(0.73,2.79) \quad 3.69$

$1.33(0.37,4.86) \quad 1.03$

$2.27(1.70,3.03) \quad 15.37$

$1.72(1.50,1.97) \quad 35.44$

$1.49(1.18,1.88) \quad 20.53$

$1.44(1.09,1.90) \quad 16.27$

$1.25(0.54,2.91) \quad 2.38$

$1.70(1.49,1.94) \quad 100.00$

NOTE: Weights are from-random effects analysis

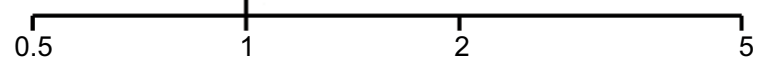

Figure 2 Forest plots of studies evaluating HRs of high pretreatment LMR among patients with OC for (A) OS and (B) PFS. Error bars indicate $95 \% \mathrm{Cl}$. Abbreviations: LMR, lymphocyte-to-monocyte ratio; OC, ovarian cancer; OS, overall survival; PFS, progression-free survival. 
A

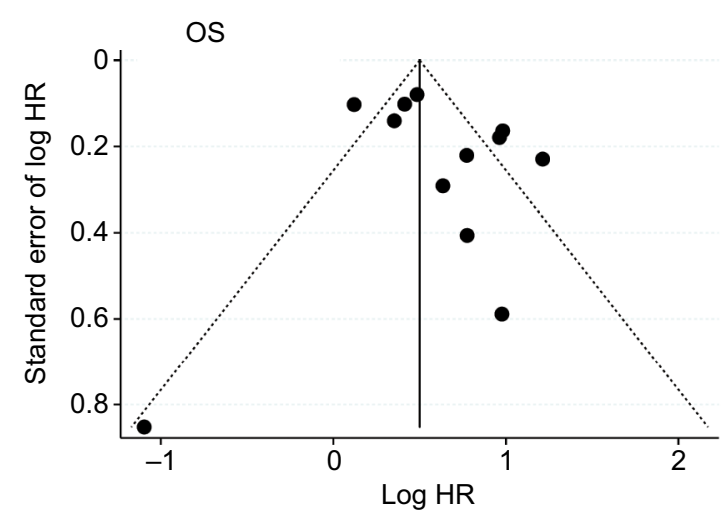

B

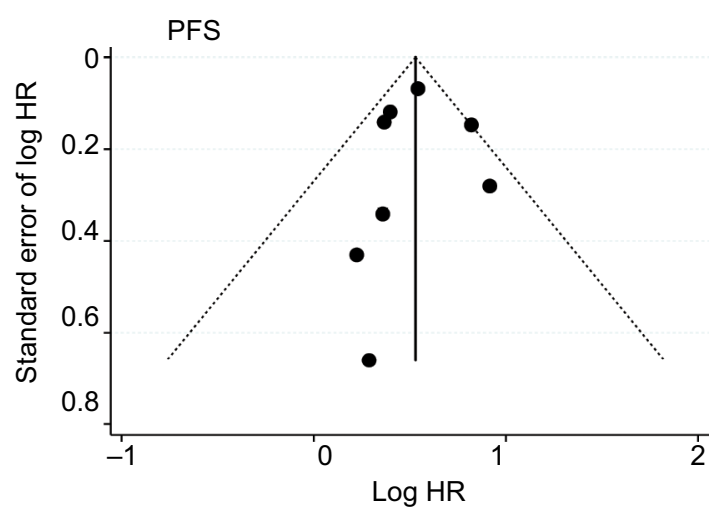

Figure 3 Funnel plots of studies evaluating HRs of high pretreatment LMR among patients with OC for (A) OS and (B) PFS. Abbreviations: LMR, lymphocyte-to-monocyte ratio; OC, ovarian cancer; OS, overall survival; PFS, progression-free survival.

invasion, migration, and metastasis and suppress the body's autoimmune response against tumor cells. ${ }^{38,39}$ In addition, LMR had been supposed to reflect the TIL/TAM ratio, as the circulating levels of lymphocytes and monocytes may indicate the formation or the presence of TILs and TAMs, and significant correlation was observed between the LMR and the TIL/TAM ratio. ${ }^{31}$ Immunotherapy has emerged as one of the most promising approaches for OC treatment, ${ }^{40}$ and change in the LMR has been supposed to be an early surrogate marker of the efficacy of nivolumab monotherapy. ${ }^{41}$ Thus, LMR represents the balance between the host's immune status and the degree of tumor progression, and it may therefore be a prognostic biomarker among OC patients.

Subgroup analyses indicated that the favorable prognostic effect of pretreatment LMR for OS was more evident in studies conducted among younger ( $<55$ years) than older patients ( $\geq 55$ years; $P$ for interaction $=0.017$ ), which was further confirmed by meta-regression analysis $(P=0.004)$. One explanation for our finding is that human aging is characterized by a gradual increase in subclinical chronic inflammation, and older people are more likely to get chronic inflammatory diseases. ${ }^{42}$ The greater severity of the inflammatory state among older OC patients may weaken the LMR's protective prognostic effect. In addition, older patients responded more efficiently to immunotherapy, such as programmed death-ligand 1 (nivolumab and pembrolizumab), and PD-L1 (atezolizumab) inhibitors also confirmed this finding. ${ }^{43,44}$

Some limitations of this meta-analysis should also be considered. First, between-study heterogeneity was significant for OS $\left(I^{2}: 76.5 \%\right)$. Based on subgroup and meta-regression analyses, age was the main source of heterogeneity, and the pooled HR results showed consistent positive relationships.
Second, most studies included herein were performed among Asian patients, while only one study examined OS among Caucasian patients, ${ }^{10}$ and no relevant studies were found for African patients. Thus, the findings of the present study might be limited to Asian patients, and the prognostic effects of LMR for other populations (eg, Caucasian or African) still need further confirmation. Third, the studies included herein differed in how the covariates were adjusted. However, the pooled estimates were similar between the maximal and minimal numbers of covariate adjustment analyses for both OS and PFS, indicating that these confounders were unlikely to significantly bias our findings (data not shown). Fourth, categorical analysis did not allow detecting the best cutoff point, which invites further studies to solve this problem. Fifth, all included studies were retrospective single-center studies, and the bias was unavoidable.

\section{Conclusion}

This meta-analysis demonstrated that higher pretreatment LMR values were associated with more favorable outcomes among OC patients, and the associations were stronger for younger patients than older patients. Future large-scale prospective clinical trials are needed to confirm the LMR's prognostic effect and its cutoff value among OC patients. Therefore, LMR is a readily available, routinely measured, and inexpensive inflammatory biomarker, and if causation and cutoff value of LMR was established, LMR could be easily applied in daily clinical practice.

\section{Acknowledgment}

The study was supported by research grants from National Natural Science Foundation of China (81602853). 


\section{Author contributions}

Study concept and design: F-FZ and SZ. Data extraction and analysis: X-PG and Y-HL. Manuscript drafting: X-PG and Y-HL. All authors contributed to data analysis, drafting and revising the article, gave final approval of the version to be published, and agree to be accountable for all aspects of the work.

\section{Disclosure}

The authors report no conflicts of interest in this work.

\section{References}

1. Torre LA, Trabert B, DeSantis CE, et al. Ovarian cancer statistics, 2018. CA Cancer J Clin. 2018;68(4):284-296.

2. Vergote I, Tropé CG, Amant F, et al; European Organization for Research and Treatment of Cancer-Gynaecological Cancer Group; NCIC Clinical Trials Group. Neoadjuvant chemotherapy or primary surgery in stage IIIC or IV ovarian cancer. N Engl J Med. 2010;363(10):943-953.

3. Macciò A, Madeddu $\mathrm{C}$. Inflammation and ovarian cancer. Cytokine. 2012;58(2):133-147.

4. Dupré A, Malik HZ. Inflammation and cancer: what a surgical oncologist should know. Eur J Surg Oncol. 2018;44(5):566-570.

5. Zhang W, Ye B, Liang W, Ren Y. Preoperative prognostic nutritional index is a powerful predictor of prognosis in patients with stage III ovarian cancer. Sci Rep. 2017;7(1):9548.

6. Zhu JY, Liu CC, Wang L, Zhong M, Tang HL, Wang H. Peripheral blood lymphocyte-to-monocyte ratio as a prognostic factor in advanced epithelial ovarian cancer: a multicenter retrospective study. J Cancer. 2017;8(5):737-743.

7. Eo WK, Chang HJ, Kwon SH, et al. The lymphocyte-monocyte ratio predicts patient survival and aggressiveness of ovarian cancer. J Cancer. 2016;7(3):289-296.

8. Kwon BS, Jeong DH, Byun JM, et al. Prognostic value of preoperative lymphocyte-monocyte ratio in patients with ovarian clear cell carcinoma. J Cancer. 2018;9(7):1127-1134.

9. Kwon BS, Lee HJ, Yang J, Song YJ, Suh DS, Lee DH, Kim KH. Prognostic value of preoperative lymphocyte-monocyte ratio in elderly patients with advanced epithelial ovarian cancer. Obstet Gynecol Sci. 2017;60(6):558-564.

10. Li Z, Hong N, Robertson M, Wang C, Jiang G. Preoperative red cell distribution width and neutrophil-to-lymphocyte ratio predict survival in patients with epithelial ovarian cancer. Sci Rep. 2017;7:43001.

11. Xiang J, Zhou L, Li X, et al. Preoperative monocyte-to-lymphocyte ratio in peripheral blood predicts stages, metastasis, and histological grades in patients with ovarian cancer. Transl Oncol. 2017;10(1):33-39.

12. Moher D, Liberati A, Tetzlaff J, Altman DG; PRISMA Group. Preferred reporting items for systematic reviews and meta-analyses: the PRISMA statement. PLoS Med. 2009;6(7):e1000097.

13. Parmar MK, Torri V, Stewart L. Extracting summary statistics to perform meta-analyses of the published literature for survival endpoints. Stat Med. 1998;17(24):2815-2834.

14. Stang A. Critical evaluation of the Newcastle-Ottawa scale for the assessment of the quality of nonrandomized studies in meta-analyses. Eur J Epidemiol. 2010;25(9):603-605.

15. Hamling J, Lee P, Weitkunat R, Ambühl M. Facilitating meta-analyses by deriving relative effect and precision estimates for alternative comparisons from a set of estimates presented by exposure level or disease category. Stat Med. 2008;27(7):954-970.

16. Riley RD, Higgins JP, Deeks JJ. Interpretation of random effects metaanalyses. BMJ. 2011;342:d549.

17. Higgins JP, Thompson SG. Quantifying heterogeneity in a meta-analysis. Stat Med. 2002;21(11):1539-1558.

18. Mander A, Clayton D. Assessing the influence of a single study in meta-analysis. Stata Tech Bull. 1999;8:108-110.
19. Wang X. The Relationship Between Preoperative Blood Lymphocyte-ToMonocyte Ratio and the Prognostic of Epithelial Ovarian Cancer. Zheng Zhou, China: The First Affiliated Hospital of Zheng Zhou University; 2017.

20. Romito A, Marchetti C, di Santo G. Monocyte-to-lymphocyte ratio as predictor of survival and response to treatment in ovarian cancer. Int $J$ Gynecol Cancer. 1913;2017:27.

21. Sun L, Song Y. Effects of lymphocyte and monocyte ratio on prognosis of epithelial ovarian cancer. Chinese Clin Oncol. 2016;10: 909-912.

22. Tang Y, Li J, Xu F, Hu H. Association between monocyte-to-lymphocyte ratio and prognosis of patients with epithelial ovarian cancer. $\mathrm{Am} J$ Obstet Gynecol Pediat. 2017;5:532-538.

23. Tian Y. Analysis of Prognostic Factors of Epithelial Ovarian Cancer. He Bei, China: Hebei Medical University; 2017.

24. Wang X, Yuan Z, Qiu H. The relationship between preoperative blood lymphocyte-to-monocyte ratio and the prognostic of epithelial ovarian cancer. Prog Obstet Gynecol. 2016;9:654-657.

25. Yang HM, Lou G. [The relationship of preoperative lymphocytemonocyte ratio and the clinicopathological characteristics and prognosis of patients with epithelial ovarian cancer]. Zhonghua Zhong Liu Za Zhi. 2017;39(9):676-680.

26. Tham T, Olson C, Khaymovich J, Herman SW, Costantino PD. The lymphocyte-to-monocyte ratio as a prognostic indicator in head and neck cancer: a systematic review and meta-analysis. Eur Arch Otorhinolaryngol. 2018;275(7):1663-1670.

27. $\mathrm{Hu} \mathrm{RJ}, \mathrm{Ma}$ JY, Hu G. Lymphocyte-to-monocyte ratio in pancreatic cancer: prognostic significance and meta-analysis. Clin Chim Acta. 2018;481:142-146.

28. Song W, Wang K, Zhang RJ, Zou SB. Prognostic value of the lymphocyte monocyte ratio in patients with colorectal cancer: a meta-analysis. Medicine (Baltimore). 2016;95(49):e5540.

29. Song W, Tian C, Wang K, Zhang RJ, Zou SB. The pretreatment lymphocyte to monocyte ratio predicts clinical outcome for patients with hepatocellular carcinoma: a meta-analysis. Sci Rep. 2017;7:46601.

30. Hu RJ, Liu Q, Ma JY, Zhou J, Liu G. Preoperative lymphocyte-tomonocyte ratio predicts breast cancer outcome: a meta-analysis. Clin Chim Acta. 2018;484:1-6.

31. Zhu Y, Li M, Bo C, et al. Prognostic significance of the lymphocyte-tomonocyte ratio and the tumor-infiltrating lymphocyte to tumor-associated macrophage ratio in patients with stage T3N0M0 esophageal squamous cell carcinoma. Cancer Immunol Immunother. 2017;66(3):343-354.

32. Balkwill F, Mantovani A. Inflammation and cancer: back to Virchow? Lancet. 2001;357(9255):539-545.

33. Sato E, Olson SH, Ahn J, et al. Intraepithelial CD8+ tumor-infiltrating lymphocytes and a high $\mathrm{CD} 8+$ /regulatory $\mathrm{T}$ cell ratio are associated with favorable prognosis in ovarian cancer. Proc Natl Acad Sci USA. 2005;102(51):18538-18543.

34. Sato E, Olson SH, Ahn J, et al. Intraepithelial CD8+ tumor-infiltrating lymphocytes and a high CD8+/regulatory $\mathrm{T}$ cell ratio are associated with favorable prognosis in ovarian cancer. Proc Natl Acad Sci U SA. 2005;102(51):18538-18543.

35. Zhang L, Conejo-Garcia JR, Katsaros D, et al. Intratumoral T cells, recurrence, and survival in epithelial ovarian cancer. $N$ Engl J Med. 2003;348(3):203-213.

36. Hwang WT, Adams SF, Tahirovic E, Hagemann IS, Coukos G. Prognostic significance of tumor-infiltrating $\mathrm{T}$ cells in ovarian cancer: a meta-analysis. Gynecol Oncol. 2012;124(2):192-198.

37. Lee KH, Kim EY, Yun JS, Park YL, Do SI, Chae SW, Park CH. The prognostic and predictive value of tumor-infiltrating lymphocytes and hematologic parameters in patients with breast cancer. BMC Cancer. 2018;18(1):938.

38. Condeelis J, Pollard JW. Macrophages: obligate partners for tumor cell migration, invasion, and metastasis. Cell. 2006;124(2):263-266.

39. Coussens LM, Werb Z. Inflammation and cancer. Nature. 2002;420(6917):860-867.

40. McCloskey CW, Rodriguez GM, Galpin KJC, Vanderhyden BC. Ovarian cancer immunotherapy: preclinical models and emerging therapeutics. Cancers (Basel). 2018;10(8):E244. 
41. Sekine K, Kanda S, Goto Y, et al. Change in the lymphocyte-tomonocyte ratio is an early surrogate marker of the efficacy of nivolumab monotherapy in advanced non-small-cell lung cancer. Lung Cancer. 2018;124:179-188.

42. Elisia I, Lam V, Hofs E, et al. Effect of age on chronic inflammation and responsiveness to bacterial and viral challenges. PLoS One. 2017;12(11):e0188881.
43. Kugel CH, Douglass SM, Webster MR, et al. Age correlates with response to anti-PD1, reflecting age-related differences in intratumoral effector and regulatory T-cell populations. Clin Cancer Res. 2018;24(21):5347-5356.

44. Elias R, Giobbie-Hurder A, McCleary NJ, Ott P, Hodi FS, Rahma O. Efficacy of PD-1 \& PD-L1 inhibitors in older adults: a meta-analysis. J Immunother Cancer. 2018;6(1):26. 


\section{Supplementary materials}

\section{Detailed search strategies for each database \\ PubMed $(\mathrm{N}=215)$}

\#1: lymphocyte-to-monocyte OR lymphocyte monocyte OR lymphocyte-monocyte OR lymphocyte to monocyte OR lymphocyte/monocyte OR LMR

\#2: ((cancer* OR carcinoma* OR neoplasm* OR malignan* OR tumour* OR tumor*) AND (ovary OR ovarian)) OR “Ovarian Neoplasms"[mesh]

\#3: \#1 AND \#2

\section{Embase $(\mathrm{N}=385)$}

\#1: ((cancer* OR carcinoma* OR neoplasm* OR malignan* OR tumour* OR tumor*) AND (ovary OR ovarian)) OR ('ovarian neoplasms'/exp)

\#2: ('lymphocyte to monocyte') OR (lymphocyte AND monocyte) OR ('lymphocyte monocyte') OR (lymphocyte AND to AND monocyte) OR (LMR) OR (lymphocyte?monocyte)

\#3: \#1 AND \#2

\section{Web of science $(\mathrm{N}=160)$}

\#1 (Ovarian Neoplasms) OR ((cancer* OR carcinoma* OR neoplasm* OR malignan* OR tumour* OR tumor*) AND (ovary OR ovarian))

\#2 (lymphocyte-to-monocyte ratio OR "lymphocyte monocyte ratio" OR "lymphocyte to monocyte ratio" OR LMR)

\section{\#3: \#1 AND \#2}

\section{Wanfang $(\mathrm{N}=165)$}

\#1 摘要: (卵巢癌+卵巢肿瘤) *摘要: (淋巴细胞) *摘 要: (单核细胞) )

\#2 摘要: (卵巢癌+卵巢肿瘤) *摘要: (LMR)

\#3 题名或关键词: (卵巢癌+卵巢肿瘤) *题名或关键 词: (淋巴细胞) *题名或关键词: (单核细胞)

\#4 题名或关键词: (卵巢癌+卵巢肿瘤) $*$ 题名或关键 词: (LMR)

\#5 主题: (卵巢癌+卵巢肿瘤) *主题: (淋巴细胞) * 主题: (单核细胞)

\#6 主题: (卵巢癌+卵巢肿瘤) *主题: (LMR)

\#7: \#1 OR \#2 OR \#3 OR \#4 OR \#5 OR \#6

\section{Chinese National Knowledge Infrastructure (CNKI;} $\mathrm{N}=73$ )

$\# 1 \mathrm{AB}=$ ( ‘卵巢癌' + ’ 卵巢肿瘤' ) and $\mathrm{AB}=$ ' 淋巴 细胞' and $\mathrm{AB}=$ ' 单核细胞'

$\# 2 A B=$ ( “卵巢癌' +' 卵巢肿瘤' ) and $A B=$ ' LMR'

\#3 TI=( '卵巢癌' +' 卵巢肿瘤, ) and TI=' 淋巴 细胞' and $\mathrm{TI}=$ ' 单核细胞'

\#4 $\mathrm{TI}=$ ( “卵巢癌' +' 卵巢肿瘤' ) and TI=' LMR'

\#5 KY=( '卵巢癌' +’ 卵巢肿瘤” ) and KY=’ 淋巴 细胞' and $K Y=$ '单核细胞'

\#6 KY=( '卵巢癌' +' 卵巢肿瘤' ) and KY=' LMR'

\#7 SU=( “卵巢癌” +' 卵巢肿瘤' ) and SU=' 淋巴 细胞' and $\mathrm{SU}=$ ' 单核细胞'

\#8 SU=( ‘卵巢癌' +' 卵巢肿瘤' ) and SU=' LMR'

\#9: \#1 OR \#2 OR \#3 OR \#4 OR \#5 OR \#6 OR \#7 OR \#8

Table SI PRISMA 2009 checklist

\begin{tabular}{|l|l|l|l|}
\hline Section/topic & No. & Checklist item & $\begin{array}{l}\text { Reported on } \\
\text { page number }\end{array}$ \\
\hline Title & $\mathrm{I}$ & Identify the report as a systematic review, meta-analysis, or both & I \\
\hline Title & $\mathbf{3}$ & $\begin{array}{l}\text { Provide a structured summary including, as applicable: background; objectives; data } \\
\text { sources; study eligibility criteria, participants, and interventions; study appraisal and } \\
\text { synthesis methods; results; limitations; conclusions and implications of key findings; } \\
\text { systematic review registration number }\end{array}$ & 3 \\
\hline Structured summary & 2 & Describe the rationale for the review in the context of what is already known & 4,5 \\
\hline Introduction & 3 & $\begin{array}{l}\text { Provide an explicit statement of questions being addressed with reference to participants, } \\
\text { interventions, comparisons, outcomes, and study design (PICOS) }\end{array}$ & 5 \\
\hline Rationale & 4 & $\begin{array}{l}\text { Indicate if a review protocol exists, if and where it can be accessed (eg, Web address), } \\
\text { and, if available, provide registration information including registration number }\end{array}$ & NA \\
\hline Objectives &
\end{tabular}


Table SI (Continued)

\begin{tabular}{|c|c|c|c|}
\hline Eligibility criteria & 6 & $\begin{array}{l}\text { Specify study characteristics (eg, PICOS and length of follow-up) and report } \\
\text { characteristics (eg, years considered, language, and publication status) used as criteria for } \\
\text { eligibility, giving rationale }\end{array}$ & 6 \\
\hline Information sources & 7 & $\begin{array}{l}\text { Describe all information sources (eg, databases with dates of coverage, contact with } \\
\text { study authors to identify additional studies) in the search and date last searched }\end{array}$ & 5 \\
\hline Search & 8 & $\begin{array}{l}\text { Present full electronic search strategy for at least one database, including any limits used, } \\
\text { such that it could be repeated }\end{array}$ & $\begin{array}{l}\text { 5, Supplementary } \\
\text { materials, pages } \\
\mathrm{I}-2\end{array}$ \\
\hline Study selection & 9 & $\begin{array}{l}\text { State the process for selecting studies (ie, screening, eligibility, included in systematic } \\
\text { review, and, if applicable, included in the meta-analysis) }\end{array}$ & 6 \\
\hline Data collection process & 10 & $\begin{array}{l}\text { Describe method of data extraction from reports (eg, piloted forms, independently, and } \\
\text { in duplicate) and any processes for obtaining and confirming data from investigators }\end{array}$ & 6 \\
\hline Data items & II & $\begin{array}{l}\text { List and define all variables for which data were sought (eg, PICOS and funding sources) } \\
\text { and any assumptions and simplifications made }\end{array}$ & 6 \\
\hline $\begin{array}{l}\text { Risk of bias in individual } \\
\text { studies }\end{array}$ & 12 & $\begin{array}{l}\text { Describe methods used for assessing risk of bias of individual studies (including } \\
\text { specification of whether this was done at the study or outcome level), and how this } \\
\text { information is to be used in any data synthesis }\end{array}$ & 7, Table S2 \\
\hline Summary measures & 13 & State the principal summary measures (eg, risk ratio and difference in means) & 7 \\
\hline Synthesis of results & 14 & $\begin{array}{l}\text { Describe the methods of handling data and combining results of studies, if done, including } \\
\text { measures of consistency }\left(\mathrm{eg}, l^{2}\right) \text { for each meta-analysis }\end{array}$ & 7 \\
\hline $\begin{array}{l}\text { Risk of bias across } \\
\text { studies }\end{array}$ & 15 & $\begin{array}{l}\text { Specify any assessment of risk of bias that may affect the cumulative evidence (eg, } \\
\text { publication bias and selective reporting within studies) }\end{array}$ & 7,8 \\
\hline Additional analyses & 16 & $\begin{array}{l}\text { Describe methods of additional analyses (eg, sensitivity or subgroup analyses, meta- } \\
\text { regression), if done, indicating which were prespecified }\end{array}$ & 7 \\
\hline \multicolumn{4}{|l|}{ Results } \\
\hline Study selection & 17 & $\begin{array}{l}\text { Give numbers of studies screened, assessed for eligibility, and included in the review, with } \\
\text { reasons for exclusions at each stage, ideally with a flow diagram }\end{array}$ & 8, Figure I \\
\hline Study characteristics & 18 & $\begin{array}{l}\text { For each study, present characteristics for which data were extracted (eg, study size, } \\
\text { PICOS, and follow-up period) and provide the citations }\end{array}$ & 8, Table I \\
\hline $\begin{array}{l}\text { Risk of bias within } \\
\text { studies }\end{array}$ & 19 & $\begin{array}{l}\text { Present data on risk of bias of each study and, if available, any outcome level assessment } \\
\text { (see item 12) }\end{array}$ & 10, Table S3 \\
\hline $\begin{array}{l}\text { Results of individual } \\
\text { studies }\end{array}$ & 20 & $\begin{array}{l}\text { For all outcomes considered (benefits or harms), present, for each study: (a) simple } \\
\text { summary data for each intervention group (b) effect estimates and Cls, ideally with a } \\
\text { forest plot }\end{array}$ & Figure 2 \\
\hline Synthesis of results & 21 & Present results of each meta-analysis done, including $\mathrm{Cls}$ and measures of consistency & $\begin{array}{l}9,10, \text { Table } 2 \text {, } \\
\text { Figure } 2\end{array}$ \\
\hline $\begin{array}{l}\text { Risk of bias across } \\
\text { studies }\end{array}$ & 22 & Present results of any assessment of risk of bias across studies (see item I5) & 10, Table S3 \\
\hline Additional analysis & 23 & $\begin{array}{l}\text { Give results of additional analyses, if done (eg, sensitivity or subgroup analyses, meta- } \\
\text { regression [see item 16]) }\end{array}$ & 9,10 \\
\hline \multicolumn{4}{|c|}{ 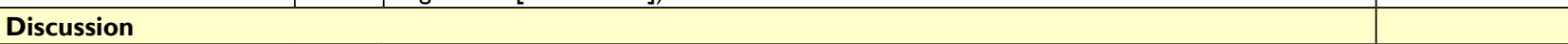 } \\
\hline Summary of evidence & 24 & $\begin{array}{l}\text { Summarize the main findings including the strength of evidence for each main outcome; } \\
\text { consider their relevance to key groups (eg, health care providers, users, and policy } \\
\text { makers) }\end{array}$ & 10 \\
\hline Limitations & 25 & $\begin{array}{l}\text { Discuss limitations at study and outcome level (eg, risk of bias), and at review level (eg, } \\
\text { incomplete retrieval of identified research and reporting bias) }\end{array}$ & 12,13 \\
\hline Conclusions & 26 & $\begin{array}{l}\text { Provide a general interpretation of the results in the context of other evidence and } \\
\text { implications for future research }\end{array}$ & 13 \\
\hline \multicolumn{4}{|l|}{ Funding } \\
\hline Funding & 27 & $\begin{array}{l}\text { Describe sources of funding for the systematic review and other support (eg, supply of } \\
\text { data); role of funders for the systematic review }\end{array}$ & 13 \\
\hline
\end{tabular}

Note: Liberati A, Altman DG, Tetzlaff J, Mulrow C, Gøtzsche PC, loannidis JPA, et al. The PRISMA Statement for Reporting Systematic Reviews and Meta-Analyses of Studies That Evaluate Health Care Interventions: Explanation and Elaboration. PLoS Med. 2009: 6(7): e I000 I00. https://doi.org/I0.137//journal.pmed.I000I00. For more information, visit: www.prisma-statement.org.

Abbreviation: NA, not available. 
Table S2 Methodological quality of all studies based on NOS for assessing the quality of each included study

\begin{tabular}{|c|c|c|c|c|c|c|c|c|c|}
\hline Study & $\begin{array}{l}\text { Representa- } \\
\text { tiveness of } \\
\text { exposed } \\
\text { cohort }\end{array}$ & $\begin{array}{l}\text { Selection } \\
\text { of non- } \\
\text { exposed } \\
\text { cohort }\end{array}$ & $\begin{array}{l}\text { Assessment } \\
\text { of exposure }\end{array}$ & $\begin{array}{l}\text { Outcome } \\
\text { not } \\
\text { present at } \\
\text { the start of } \\
\text { the study }\end{array}$ & $\begin{array}{l}\text { Compara- } \\
\text { bility based } \\
\text { on the } \\
\text { design or } \\
\text { analysis }\end{array}$ & $\begin{array}{l}\text { Assessment } \\
\text { of outcome }\end{array}$ & $\begin{array}{l}\text { Follow- } \\
\text { up long } \\
\text { enough for } \\
\text { outcomes }\end{array}$ & $\begin{array}{l}\text { Adequacy } \\
\text { of follow-up }\end{array}$ & $\begin{array}{l}\text { Total } \\
\text { score }\end{array}$ \\
\hline Eo et $\mathrm{al}^{\prime}$ & $\mathrm{I}$ & $\mathrm{I}$ & $\mathrm{I}$ & 1 & 2 & 0 & 0 & 0 & 6 \\
\hline Sun and Song ${ }^{2}$ & I & I & $\mathrm{I}$ & I & 2 & 0 & 0 & 0 & 6 \\
\hline Wang et $\mathrm{al}^{3}$ & $\mathrm{I}$ & $\mathrm{I}$ & $\mathrm{I}$ & $\mathrm{I}$ & 2 & 0 & 0 & 0 & 6 \\
\hline Kwon et al ${ }^{4}$ & $\mathrm{I}$ & $\mathrm{I}$ & $\mathrm{I}$ & $\mathrm{I}$ & 2 & 0 & 0 & 0 & 6 \\
\hline Li et al ${ }^{5}$ & $\mathrm{I}$ & $\mathrm{I}$ & $\mathrm{I}$ & $\mathrm{I}$ & 2 & 0 & 1 & 1 & 8 \\
\hline Xiang et $\mathrm{a}^{6}$ & $\mathrm{I}$ & $\mathrm{I}$ & $\mathrm{I}$ & 1 & $\mathrm{I}$ & 0 & 0 & $\mathrm{I}$ & 6 \\
\hline Zhang et $\mathrm{al}^{7}$ & $\mathrm{I}$ & $\mathrm{I}$ & $\mathrm{I}$ & $\mathrm{I}$ & $\mathrm{I}$ & 0 & 0 & 0 & 5 \\
\hline Zhu et al ${ }^{8}$ & $\mathrm{I}$ & $\mathrm{I}$ & $\mathrm{I}$ & $\mathrm{I}$ & 2 & 0 & $\mathrm{I}$ & 0 & 7 \\
\hline Tang et $\mathrm{al}^{9}$ & $\mathrm{I}$ & $\mathrm{I}$ & $\mathrm{I}$ & $\mathrm{I}$ & 2 & 0 & $\mathrm{I}$ & 0 & 7 \\
\hline $\operatorname{Tian}^{10}$ & $I$ & $I$ & $I$ & 1 & $I$ & 0 & $I$ & 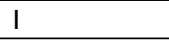 & 7 \\
\hline Yang and Lo" & $\mathrm{I}$ & $\mathrm{I}$ & $\mathrm{I}$ & 1 & 2 & 0 & $\mathrm{I}$ & 0 & 7 \\
\hline Kwon et al ${ }^{12}$ & $I$ & $I$ & $\mathrm{I}$ & I & 2 & 0 & 0 & 0 & 6 \\
\hline
\end{tabular}

Abbreviation: NOS, Newcastle-Ottawa Scale.

Table S3 Meta-regression analyses of the associations between pretreatment LMR and survival among OC patients

\begin{tabular}{|l|l|l|l|l|l|}
\hline & Coefficient & Standard error & T-value & $P$-value & $95 \%$ Cl of intercept \\
\hline OS & & & & & \\
Year of publication & 0.0820097 & 0.2491714 & 0.33 & 0.749 & $(-0.4731787,0.637198 I)$ \\
Age & -0.0738882 & 0.0200856 & -3.68 & 0.004 & $(-0.1186417,-0.0291346)$ \\
Sample size & -0.0008594 & 0.0005413 & -1.59 & 0.143 & $(-0.0020655,0.0003466)$ \\
LMR cutoff value & 0.2008357 & 0.129754 & 1.55 & 0.153 & $(-0.0882742,0.4899455)$ \\
NOS score & -0.1728062 & 0.1330581 & -1.30 & 0.223 & $(-0.4692782,0.1236658)$ \\
PFS & -0.1952826 & 0.2098772 & & & \\
Year of publication & -0.0333006 & 0.0275148 & -0.93 & 0.388 & $(-0.7088336,0.3182684)$ \\
Age & -0.0000113 & 0.0004759 & -1.21 & 0.272 & $(-0.1006267,0.0340256)$ \\
Sample size & 0.0189409 & 0.1054612 & -0.02 & 0.982 & $(-0.0011757,0.001153 I)$ \\
LMR cutoff value & -0.1618594 & 0.0787455 & 0.18 & 0.863 & $(-0.2391134,0.2769952)$ \\
NOS score & & -2.06 & 0.086 & $(-0.3545426,0.0308238)$ \\
\hline
\end{tabular}

Abbreviations: LMR, lymphocyte-to-monocyte ratio; NOS, Newcastle-Ottawa Scale; OC, ovarian cancer; OS, overall survival; PFS, progression-free survival.

\section{References}

1. Eo WK, Chang HJ, Kwon SH, et al. The lymphocyte-monocyte ratio predicts patient survival and aggressiveness of ovarian cancer. $J$ Cancer. 2016;7(3):289-296.

2. Sun L, Song Y. Effects of lymphocyte and monocyte ratio on prognosis of epithelial ovarian cancer. Chinese Clinical Oncology. 2016;10:909-912.

3. Wang X, Yuan Z, Qiu H. The relationship between preoperative blood lymphocyte-to-monocyte ratio and the prognostic of epithelial ovarian cancer. Progi Obstet Gynecol. 2016;9:654-657.

4. Kwon BS, Lee HJ, Yang J, Song YJ, Suh DS, Lee DH, Kim KH. Prognostic value of preoperative lymphocyte-monocyte ratio in elderly patients with advanced epithelial ovarian cancer. Obstet Gynecol Sci. 2017;60(6):558-564.

5. Li Z, Hong N, Robertson M, Wang C, Jiang G. Preoperative red cell distribution width and neutrophil-to-lymphocyte ratio predict survival in patients with epithelial ovarian cancer. Sci Rep. 2017;7:43001.

6. Xiang J, Zhou L, Li X, et al. Preoperative Monocyte-to-lymphocyte ratio in peripheral blood predicts stages, metastasis, and histological grades in patients with ovarian cancer. Transl Oncol. 2017;10(1):33-39.
7. Zhang W, Ye B, Liang W, Ren Y. Preoperative prognostic nutritional index is a powerful predictor of prognosis in patients with stage III ovarian cancer. Sci Rep. 2017;7(1):9548.

8. Zhu JY, Liu CC, Wang L, Zhong M, Tang HL, Wang H. Peripheral blood lymphocyte-to-monocyte ratio as a prognostic factor in advanced epithelial ovarian cancer: a multicenter retrospective study. J Cancer. 2017;8(5):737-743.

9. Tang Y, Li J, Xu F, Hu H. Association between monocyte-to-lymphocyte ratio and prognosis of patients with epithelial ovarian cancer. Am J Obstet Gynecol Pediat. 2017;5:532-538.

10. Tian Y. Analysis of Prognostic Factors of Epithelial Ovarian Cancer. He Bei, China: Hebei Medical University; 2017.

11. Yang HM, Lou G. The relationship of preoperative lymphocyte-monocyte ratio and the clinicopathological characteristics and prognosis of patients with epithelial ovarian cancer. Zhonghua Zhong Liu Za Zhi. 2017;39(9):676-680.

12. Kwon BS, Jeong DH, Byun JM, et al. Prognostic value of preoperative lymphocyte-monocyte ratio in patients with ovarian clear cell carcinoma. J Cancer. 2018;9(7):1127-1134. 


\section{Publish your work in this journal}

Cancer Management and Research is an international, peer-reviewed open access journal focusing on cancer research and the optimal use of preventative and integrated treatment interventions to achieve improved outcomes, enhanced survival and quality of life for the cancer patient. The manuscript management system is completely online and includes a very quick and fair peer-review system, which is all easy to use. Visit http://www.dovepress.com/testimonials.php to read real quotes from published authors.

Submit your manuscript here: https://www.dovepress.com/cancer-management-and-research-journal 